\title{
Conferências Estaduais de Saúde em Santa Catarina: memória e perfil sócio-político dos delegados
}

\author{
Tânia Regina Kruger
}

\begin{abstract}
Conferências Estaduais de Saúde em Santa Catarina: memória e perfil sócio-político dos delegados

Resumo: O objetivo deste texto é refletir sobre o significado das Conferências de Saúde no contexto do SUS e de apresentar elementos da memória das Conferências sete Estaduais de Saúde em Santa Catarina. Para recuperar dados objetivos das Conferências Estaduais de Saúde que começaram a acontecer após da regulamentação do SUS em 1990 foi realizada pesquisa bibliográfica e documental para recuperar dados do seu processo organizativo. O texto se completa com a apresentação comparativa do perfil sócio-político dos participantes da $5^{\mathrm{a}}$ e $6^{\mathrm{a}}$ Conferência Estadual de Saúde de Santa Catarina realizadas em 2007 e 2011 respectivamente. A pesquisa contempla dados dos quatro segmentos participantes (usuários, trabalhadores, gestores e prestadores de serviços privados), em relação ao sexo, idade, formação, ocupação e participação política.
\end{abstract}

Palavras-Chave: Conferência de Saúde. Participação social. SUS

State Health Conferences in Santa Catarina: memoryand socio-political profile of the delegates Abstract: The aim of this paper is to make a short reflection on the meaning of the Health Conferences in the context of SUS and present memory elements from the State Health Conferences in Santa Catarina. The history of popular participation in health and in the SUS implementation process in the state is yet to be recovered and systematized. In this text we present descriptions made from literature and documentary research in order to retrieve objective data from the State Health Conferences that started happening after the SUS regulations in 1990. The text is completed with the comparative presentation of the socio-political profile from the participants of the 5th and 6th State Conference of Health of Santa Catarina held in 2007 and 2011 respectively. The survey includes data from participants of the four segments (users, workers, managers and private service providers) in relation to sex, age, education, occupation and political participation.

Keywords: Health Conference. Participation. SUS

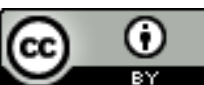

Esta obra foi licenciada sob uma Licença Creative Commons - Atribuição 3.0 Não Adaptada. 


\section{Introdução}

Este artigo procura refletir brevemente sobre o significado das Conferências de Saúde no contexto do SUS e tem o objetivo principal de apresentar um pouco da memória das Conferências Estaduais de Saúde em Santa Catarina entre 1990 e 2015. A história da participação popular em saúde, especificamente no Movimento da Reforma Sanitária e no processo de implementação do SUS, ainda está por ser recuperada e sistematizada cuidadosamente neste estado. Existem algumas pesquisas que retratam momentos ou experiências localizadas ${ }^{1}$, mas ainda necessita-se de estudos que revelam o processo e a particularidade da história catarinense de participação popular na construção e implementação o SUS.

Este artigo foi construído a partir de um estudo exploratório da temática e com metodologia qualitativa e quantitativa. As descrições realizadas pretendem recuperar dados objetivos da história e do perfil dos participantes das Conferências Estaduais de Saúde em Santa Catarina que começaram a acontecer após da regulamentação do SUS em $1990^{2}$.

No caso deste texto se construiu a partir de pesquisa bibliográfica e documental referente às Conferências de Saúde. E particularmente sobre estas plenárias em Santa Catarina foram consultados documentos emitidos pela Secretaria do Estado da Saúde - SES e pelo Conselho Estadual de Saúde - CES, como decretos e portarias tratando da convocação e organização, atas, documentos de orientação sobre a organização das etapas municipais, forma de indicação dos delegados e envio de propostas para a etapa estadual, programação, regimento interno e Relatórios Finais destas sete plenárias.

Os dados colhidos e tabulados do perfil sócio-político dos participantes da $5^{\mathrm{a}}$ e $6^{\mathrm{a}}$ Conferência Estadual de Saúde de Santa Catarina em 2007 e 2011 respectivamente, foram colhidos a partir de duas pesquisas realizadas em cada uma das plenárias ${ }^{3}$. Foram entrevistados 201 delegados participantes de 118 municípios catarinenses em 2007 e 437 delegados participantes em 2011. A intenção das entrevistas foi conhecer um pouco mais do perfil sócio, político e cultural de cada um dos quatro segmentos que participam como

\footnotetext{
${ }^{1}$ a) ROS, Marco Aurélio da. Um drama estratégico: o movimento sanitário e sua expressão num município de Santa Catarina. ENSP/FIOCRUZ. Rio de Janeiro, 1991 Dissertação de Mestrado; b) MAGAJEWSKI, F. R. L. Seletividade Estrutural e a construção do Sistema único de Santa Catarina no período 1987-1990. Florianópolis; UFSC. Dissertação de Mestrado em Administração, 1994; c) KLEBA, M. E. Descentralização do Sistema de Saúde no Brasil: limites e possibilidades de uma estratégia para o empoderamento. Chapecó: Editora Argos, 2005; d) KRUGER, T.R. As conferências de saúde e os planos municipais de saúde: considerações sobre o significado da participação popular em Santa Catarina. Florianópolis: DIOESC, 2012.

${ }^{2}$ A $7^{\circ}$ Conferência Estadual de Saúde em Santa Catarina está prevista para se realizar entre 23, 24 e 25 de setembro de 2015 e elegerá 100 delegados para etapa nacional.

${ }^{3}$ Pesquisa da $5^{\text {a }}$ Conferência: Projeto de pesquisa Conferência Estadual de Saúde/SC: o perfil dos seus participantes, foi aprovado pelo Comitê de Ética em Pesquisa da SES (CEP/SES-SC) no processo de número 0012.0908-07. A aplicação do questionários/entrevistas durante a Conferência contou coma colaboração de alunos do curso de Serviço Social da UFSC: Adriana K. Notsume, Patrícia M. Moraes e Samuel S. dos Santos.

Pesquisa da $6^{\text {a }}$ Conferência: Projeto de pesquisa Conferência Estadual de Saúde/SC: organização, perfil dos seus participantes e significados das proposições, foi aprovado em 26/09/2011 pelo Comitê de Ética em Pesquisa da SES (CEP/SES-SC) no processo de número 0247.1409-11. A aplicação do questionários durante a Conferência contou com a colaboração de alunos do curso de Serviço Social da UFSC: Arícia Furlanetto, Cória H. V. de Assunção, Daiana Nardino Dias, Glauco P.B, Karla Garcia Reboli e Uris Ruiz Valiente. Estes estudantes também se revezaram como observadores nas reuniões da Comissão Organizadora e do Conselho Estadual de Saúde e puderam observar um pouco das tensões do processo de organização da $6^{\text {a }}$ Conferência Estadual de Saúde.
} 
delegados das Conferências. Os dados foram tabulados especialmente considerando o segmento representativo e estão apresentados em forma de tabelas.

Os resultados desta pesquisa podem fornecer elementos para avaliar o grau democratização e gestão da política de saúde, em sua relação com as bandeiras do Movimento da Reforma Sanitária e as necessidades dos vários segmentos em relação a saúde. O estudo pode contribuir para a discussão de temas como o controle social e a gestão participativa, que apesar de estarem continuamente em debate, ainda são desafios que se colocam cotidianamente para os integrantes e os defensores dos espaços colegiados das Conferências e dos Conselhos. Pode também auxiliar os gestores e demais sujeitos sociais na gestão pública da saúde na construção desse novo padrão de gestão que inclui o controle social e a participação da população. O estudo do perfil dos participantes das Conferências revela como novos sujeitos sociais estão conseguindo ou não se inserir nestes espaços públicos de debate. Também expressa à permeabilidade destes espaços públicos a novos sujeitos e demandas populares. Há no Brasil o desafio histórico de incorporar as demandas populares na agenda da administração pública e as Conferências podem ser um destes espaços.

O texto se estrutura da seguinte forma. Um item inicial que conceitua e caracteriza o papel histórico e político das Conferências de Saúde no âmbito do SUS. Na sequencia os dados sistematizados das Conferências Estaduais de Saúde em Santa Catarina, tratando de aspectos de sua organização e realização.

\section{2 - Conferencia de Saúde: seu significado e seu papel}

As Conferências Nacionais de Saúde possuem uma trajetória desde 1940 no Brasil. Até 1980, aconteceram numa conjuntura fechada, exceto a de 1963. Nelas tinham assento representante do governo, da medicina previdenciária, da medicina filantrópica e privada. A partir de 1986, no período de redemocratização, com a $8^{\text {a }}$ Conferência, elas adquirem um caráter democrático e são mobilizadoras de diferentes segmentos sociais nas três esferas de governo.

Como resultado deste processo a Constituição de 1988 reconheceu como uma das diretrizes do SUS a participação da comunidade que foi regulamentada na lei $n^{\circ}$. 8.142/1990 e organizou esta participação em dois colegiados que são a Conferência e o Conselho de saúde nas três esferas de governo. Nesta Lei a Conferência de Saúde é caracterizada como uma plenária que se reunirá a cada quatro anos com a representação dos vários segmentos sociais, para avaliar a situação de saúde e propor as diretrizes para a formulação da política de saúde nos níveis correspondentes, convocada pelo Poder Executivo ou, extraordinariamente, por esta ou pelo Conselho de Saúde.

Desse modo as Conferencias de Saúde se materializam como instrumentos de gestão participativa do SUS e devem acontecer em períodos regulares, cumprindo o papel de fazer grandes avaliações e de propor diretrizes (princípios, projetos, políticas e metas), de médio e longo prazo, para orientar o planejamento e a gestão dos serviços de saúde.

As Conferências surgem como instâncias nas quais (pelo menos potencialmente) os usuários, trabalhadores da saúde, prestadores de serviços privados e filantrópicos e gestores públicos como representante de seus segmentos podem participar da formulação e avaliação da política. Enquanto os Conselhos têm a função de formular estratégias, aprovar econtrolar a execução do planejamento, as plenárias das Conferências são mobilizadoras, desde núcleos 
inframunicipais até sua condensação na esfera federal, e por isto são caracterizadas como o grande evento nacional de avaliação e de proposições sobre o SUS.

$\mathrm{Na}$ perceptiva deste trabalho as Conferências de Saúde estão representando uma socialização do debate político e estão abrindo canais à participação para segmentos sociais antes excluídos do debate sobre as decisões públicas e governamentais. Os espaços das Conferências e Conselhos, mesmo que formalmente delimitados (institucionalizados), estão possibilitando que muitos representantes de vários segmentos sociais de usuários do SUS e muitos trabalhadores da saúde adentrem as autoritárias e isoladas fronteiras que marcam a história da administração pública brasileira e possam conhecer a dinâmica da gestão e fazer proposições sobre as políticas de saúde. Ainda se constituem como oportunidade de socialização da política e da construção de outra hegemonia articulada pelos princípios da democracia popular. Mesmo que, de fato, estas instâncias após quase três décadas de vida não tenham conseguido mudança de paradigma no conteúdo e na forma das políticas governamentais, pois lhe faltam teses e propostas de direção da política, estão introduzindo novas configurações no âmbito público-estatal, e, num nível restrito, estão possibilitando a socialização de informações sobre projetos, serviços, financiamento, burocracias e rotinas de convênios e do processo da gestão.

O reconhecimento formal do espaço das Conferências e Conselhos na Lei 8.142/90, ainda que represente certa acomodação dos interesses dentro da ordem, é resultado de um processo de luta de classes, onde havia disputa de direção ideopolítica. É certo que nos anos de 1990 e início de 2000 este processo de luta de classes sofreu um refluxo significativo, mas ainda, não é possível compartilhar com a visão de que se transformaram apenas em espaços de consenso e pactuação. Concordamos com Bravo (2001:47) que as Conferências e os Conselhos são:

Espaços tensos em que os diferentes interesses estão em disputa [...] devem ser visualizados como locus de fazer político, como espaço contraditório, como uma nova modalidade de participação, ou seja, a construção de uma cultura alicerçada nos pilares da democracia participativa.

As Conferências ao reunir diferentes sujeitos sociais (usuários, trabalhadores, governo e prestadores privados e filantrópicos para o SUS), têm a possibilidade de ser reorientadoras de práticas, prioridades e planos de ação para a política de saúde nos respectivos níveis de governo. Assim, o espaço das Conferências e Conselhos tem sido reconhecido em diferentes âmbitos (políticos, acadêmicos, ONGs), de maneira quase inquestionável, como instrumentos de controle social das políticas de saúde e que intermedeiam a relação Estado e sociedade. Entendemos também que são colegiados contraditórios e tensos, permeados por diferentes interesses sociais. As necessidades imediatas dos serviços de saúde por vezes solicitam que se realizem pactuações temporárias e direcionadas para alguma prioridade de serviço, mas consenso com esta composição é difícil de visualizar, caso algum dos segmentos não se coloque em posição subordinada ou silencie.

As Conferências são espaços mais amplos de participação do que os Conselhos, por serem mais informais e envolveram plenárias ascendentes nas diferentes esferas da federação. Através das pré-conferências são mobilizados núcleos organizados desde a esfera inframunicipal que de outra forma os gestores teriam dificuldade de tomar conhecimento das demandas dos usuários. Do lado da instituição, pode ser um espaço de participação dos 
servidores públicos, que quase sempre não dispõem de mecanismos para o encaminhamento de suas demandas e de diálogo com o próprio chefe. Por sua vez os prestadores filantrópicos e privados de serviços para o SUS dão de cara com o povo anônimo da fila e da demanda reprimida. Entretanto, as plenárias também se configuram em espaços de manipulação, de reivindicações isoladas, de propostas consistentes e de experiências bem sucedidas.

Além disso, as Conferências representam uma caixa de reverberação ou babel político-ideológica, onde diferentes vozes políticas deixam marcas e apresentam suas necessidades de saúde nas proposições que constam no Relatório. Por isso, elas podem ser um espaço para se ouvir, com anos de antecedência, propostas primárias que gradualmente poderão ser maturadas e se transformarem, nos anos seguintes, em estratégias políticas e serviços.

As Conferências materializam a descentralização participativa, propiciando possibilidades de planejamento ascendente e participativo. Principalmente nas médias e grandes cidades, acontecem plenárias de saúde coordenadas por segmentos de usuários e/ou trabalhadores e pré-conferências ${ }^{4}$ distritais e locais. Entidades Nacionais como a CUT, CNBB/Pastoral da Saúde e da Criança, Centro Brasileiro de Estudos em Saúde Coletiva CEBES, Associação Brasileira de Saúde Coletiva - ABRASCO, universidades, Conselhos Federais de profissionais de saúde, Federações/Associações nacionais de portadores de patologias, de doenças específicas, de mulheres, de negros, de índios, de deficientes também se mobilizam e lançam documentos com avaliações do SUS e proposições para as Conferências. Desse modo, para além da formalidade das Conferências elas são dinamizadas por entidades, movimentos e fóruns que alimentam a tensão e o convívio dos interesses públicos, corporativos e privados dentro do SUS.

Uma Conferência Estadual, por exemplo, em que pese toda a fase de debates prévios, culmina no encontro de delegados escolhidos paritariamente em plenárias em todos os municípios do estado. Encontro no qual esses participantes discutem propostas diversas, examinam diferentes leituras, negociam e disputam entre si posições e, por fim, aprovam certas análises e propostas de diretrizes para as políticas de saúde que se condensam no Relatório Final. Este Relatório deve orientar o planejamento e a gestão da Secretaria Estadual de Saúde nos 4 anos seguintes assim como será encaminhado para subsidiar o debate da Conferencia Nacional junto com os demais dos 26 estados da federação.

\section{3 - Memória das Conferências Estaduais de Saúde em Santa Catarina}

As Conferências Estaduais de Saúde em Santa Catarina começaram a acontecer após da regulamentação do SUS $^{5}$ em 1990: a $1^{\mathrm{a}}$ em 1992, a $2^{\mathrm{a}}$ em 1996, a $3^{\mathrm{a}}$ no ano 2000, a $4^{\mathrm{a}}$ em 2003, a $5^{\mathrm{a}}$ em 2007, a $6^{\mathrm{a}}$ em 2011 e a $7^{\mathrm{a}}$ em 2015. Estas foram às etapas estaduais de Santa Catarina da $9^{\mathrm{a}}$ a $15^{\mathrm{a}}$ Conferência Nacional de Saúde, realizadas no mesmo ano.

\footnotetext{
4 "Pré-conferências são espaços que permitem uma maior divulgação da Conferência, pode ter várias finalidades: escolher os delegados, principalmente onde não há associações formais; estimular a participação popular; levantar os problemas de saúde; levantar dados primários para elaborar as diretrizes das políticas de saúde. Devem ser realizadas nos dois meses antes da Conferência" (CONASEMS. Conferências Municipais de Saúde passo a passo, jul/2003, p. 10).

5 Vale destacar que em Santa Catarina não houve Conferência Estadual como etapa da $8^{\circ}$ Conferência Nacional, mas aconteceu uma reunião ampliada (uma espécie de pré-conferência) que reuniu vários segmentos sociais que se identificavam e participavam das lutas da Reforma Sanitária.
} 
Os registros das três primeiras plenárias estão dispersos em vários setores da Secretaria de Estado da Saúde e não arquivados de forma organizada, por isto não são de fácil localização. Uma breve caracterização das Conferências de 1986 a 2000 podem ser encontradas junto ao corpo do Relatório da $4^{\circ}$ Conferência de Saúde, num texto elaborado por Magajewski (2003). Já os dados da $4^{\mathrm{a}}$ a $7^{\mathrm{a}}$ Conferência Estadual estão disponibilizados online no site da SES/SC. Os documentos localizados para recuperar a memória destas plenárias estaduais seja impresso ou online não refletem uma sistematização que permite o leitor reconhecer todo o processo de organização e realização. Destaca-se que não foram localizados os relatórios da pré-conferência de 1986 e os relatórios da $1^{\mathrm{a}}$ e da $2^{\mathrm{a}}$ Conferência Estadual. Das demais etapas a única que possui um relatório sistematizado e que reflete o processo da Conferência é a $4^{a}$ Conferência de 2003. O documento das propostas das plenárias estaduais de 2000, 2007 e 2011, não foram organizados na forma completa de um Relatório Final. Na $5^{\mathrm{a}}$ e $6^{\mathrm{a}}$ plenária o Relatório Final está no site da SES em arquivos soltos, alguns sem identificação institucional e não datados. Ainda, buscamos nas atas do Conselho Estadual de Saúde no final de 2011 e no ano de 2012 referencias de avaliação e de remissões as propostas aprovadas na $6^{\mathrm{a}}$ Conferência Estadual e nada encontramos. Por vezes recorremos a conversas com as pessoas que estavam na comissão organizadora de cada Conferência ${ }^{6}$ para compreender um pouco do processo e mesmo tentar localizar algum documento. Da $7^{\text {a }}$ Conferência Estadual os documentos também estão no site ainda de forma mais dispersa e com menos informações sobre o processo de organização. O documento com as propostas aprovadas e o nome dos delegados eleitos para etapa nacional se encontram apenas no site da Conferência Nacional ${ }^{7}$. Estas nossas observações sobre os arquivos destas plenária encontram em Magajewski (2000) uma dura avaliação: "a memória institucional [das Conferências de Saúde em Santa Catarina foi], sistematicamente agredida pelo descaso dos gestores da área da saúde no estado".

Desse modo decidiu-se, sistematizar no Quadro 1, alguns elementos desta memória das Conferências. Contudo, restam algumas lacunas, as quais se sugere que sejam estudadas em futuras pesquisas.

\footnotetext{
${ }^{6}$ A história das Conferências Estaduais de Saúde em Santa Catarina não foi estudada e nem sistematizada por isto foram realizados conversas esparsas com Marco Aurélio da Ros, Flávio R. L. Magajewski, Clair Castilhos, Julio Cesar Marchi, Lucio Botelho e Jaqueline Nehring em vários momentos de nossa trajetória como pesquisadora deste tema.

Relação dos delegados de Santa Catarina para etapa nacional in. http://conferenciasaude15.org.br/wpcontent/uploads/2015/11/Santa-Catarina1.pdf. Documento com as cinco prioridade de Santa Catarina em cada um dos 8 eixos temáticos http://conferenciasaude15.org.br/wp-content/uploads/2015/11/Santa-Catarina.pdf. Acesso em 10/03/2016.
} 
Quadro 1 - Caracterização das Conferências Estaduais de Saúde em Santa Catarina de 1986 a $2011^{8}$

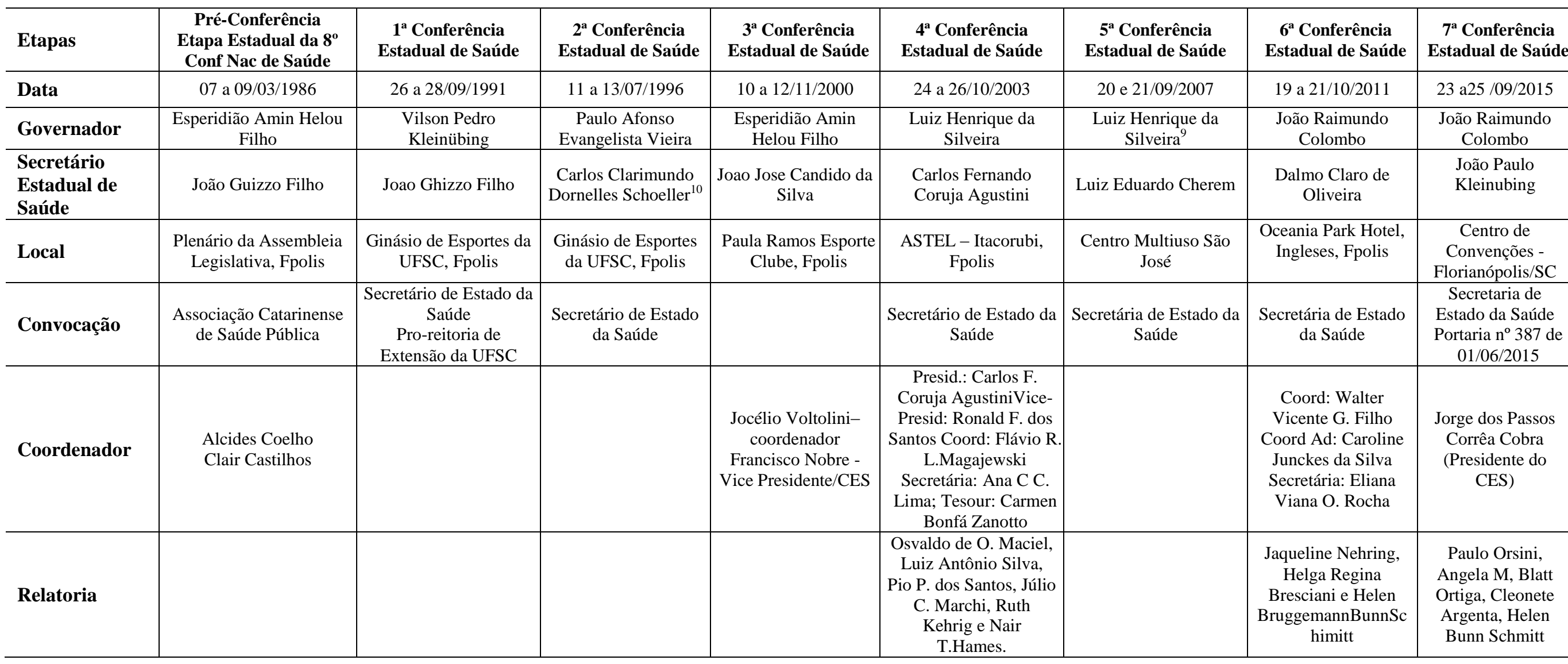

${ }^{8}$ Fonte: SANTA CATARINA. Relatórios e documentos das Conferências Estaduais de Saúde, SC. 1990 a 2015. SANTA CATARINA. Atas. Conselho Estadual de Saúde. In. http://portalses.saude.sc.gov.br/index.php?option=com_content\&view=article\&id=1384\&Itemid=425. Elaboração da Autora.

${ }^{9} \mathrm{Na}$ data da plenária Carmen Bonfá Zanotto era Secretária de Estado da Saúde em Exercício.

${ }^{10}$ Vale destacar que o secretario Carlos Clarimundo Dornelles Schoeller assumiu a pasta 8 dias antes da plenária estadual. A Conferência foi organizada na gestão de Ronald

Moura Fiuza, que esteve na gestão no período de 01/01/1995 a 18/06/1996. 


\begin{tabular}{|c|c|c|c|c|c|c|c|}
\hline Tema & & $\begin{array}{l}\text { Municipalização é o } \\
\text { caminho }\end{array}$ & $\begin{array}{l}\text { Efetivando o SUS: } \\
\text { acesso, qualidade e } \\
\text { humanização na at. à } \\
\text { saúde com controle } \\
\text { social. }\end{array}$ & $\begin{array}{l}\text { Saúde: um direito de } \\
\text { todos e dever do } \\
\text { Estado - A saúde que } \\
\text { temos e o SUS que } \\
\text { queremos }\end{array}$ & $\begin{array}{l}\text { Saúde e qualidade de } \\
\text { vida: políticas de } \\
\text { estado e } \\
\text { desenvolvimento }\end{array}$ & $\begin{array}{l}\text { Todos usam o } \\
\text { SUS! }{ }^{11}\end{array}$ & $\begin{array}{l}\text { Saúde pública de } \\
\text { qualidade para } \\
\text { cuidar bem das } \\
\text { pessoas: direito do } \\
\text { povo brasileiro } \\
\end{array}$ \\
\hline $\mathrm{N}^{\circ}$ participantes & 40 & $\begin{array}{c}438 \text { delegados } \\
500 \text { observadores }\end{array}$ & 1200 delegados & $\begin{array}{c}996 \text { delegados } \\
341 \text { observadores } \\
\text { (249 municípios) }\end{array}$ & $\begin{array}{l}1007 \text { delgados } \\
19 \text { observadores } \\
270 \text { municípios }\end{array}$ & $\begin{array}{l}1679 \text { inscritos } \\
964 \text { credenciados }\end{array}$ & $\begin{array}{c}1880 \text { delegados } \\
64 \text { conselheiros } \\
\text { estaduais de saúde } \\
188 \text { convidados } \\
\text { pelo CES }\end{array}$ \\
\hline $\begin{array}{l}\text { Delegados para } \\
\text { etapa nacional }\end{array}$ & & $\begin{array}{c}26 \text { delegados } \\
22 \text { credenciados }\end{array}$ & 58 & 76 & 83 & 96 & 100 \\
\hline Conferencis-tas & Sérgio Arouca & $\begin{array}{c}\text { Augusto Viveiros } \\
\text { (MS); M }{ }^{\mathrm{a}} \text { Luiza Jaeger } \\
\text { (SMS/POA); Luciano } \\
\text { P. Junqueira } \\
\text { (FUNDAP/SP); Joana } \\
\text { Azevedo (MS) } \\
\text { M }^{\mathrm{a}} \text { Teresa Leopardi } \\
\text { (UFSC), Nelson R. } \\
\text { Santos (CNS) }\end{array}$ & & $\begin{array}{c}\text { Fernando Coruja } \\
\text { Agustini; Beatriz A. } \\
\text { Paiva, Julio C. Marchi, } \\
\text { Marco A. Da Ros, } \\
\text { Nelson Rodrigues dos } \\
\text { Santos, Herlval Pina } \\
\text { Ribeiro, Ana Maria } \\
\text { Costa, Lúcio Barcellos, } \\
\text { Norberto Rech e Caco } \\
\text { Xavier } \\
\end{array}$ & $\begin{array}{c}\text { Ronald Ferreira dos } \\
\text { Santos - CNS } \\
\text { Armando Raggio PR } \\
\text { Celso Dellagiustina } \\
\text { CONASEMS/SC } \\
\text { Clair Castilhos - UFSC }\end{array}$ & $\begin{array}{c}\text { Eliane Cruz, } \\
\text { Nelson Rodrigues } \\
\text { dos Santos e } \\
\text { Gilson Carvalho }\end{array}$ & $\begin{array}{l}\text { Heider Aurélio } \\
\text { Pinto - MS } \\
\text { Jair Brandão - } \\
\text { SES/PE }\end{array}$ \\
\hline $\begin{array}{l}\text { Principais } \\
\text { articuladores }\end{array}$ & $\begin{array}{l}\text { Clair Castilhos } \\
\text { Alcides Coelho }\end{array}$ & & Volnei Morastoni & $\begin{array}{l}\text { Flávio Magajewski } \\
\text { Júlio C. Marchi, } \\
\text { Ana C. C. Lima }\end{array}$ & & $\begin{array}{c}\text { Jaqueline } \\
\text { Nehring,Gilberto A } \\
\text { Scussiato, Helga } \\
\text { R.Bresciani e Helen } \\
\text { B. B.Schimit }\end{array}$ & $\begin{array}{c}\text { Jorge dos Passos } \\
\text { Corrêa Cobra, Paulo } \\
\text { Luiz Cantanhede } \\
\text { Orsini } \\
\text { Alexandre Cunha } \\
\text { dos Santos } \\
\end{array}$ \\
\hline $\begin{array}{l}\text { Etapas } \\
\text { municipais e/ou } \\
\text { regionais }\end{array}$ & & $\begin{array}{c}13 \text { regionais } 4000 \\
\text { delegados e } 1000 \\
\text { observadores }\end{array}$ & $\begin{array}{c}170 \text { Conferências } \\
\text { Municipais e } 70 \\
\text { regionais }\end{array}$ & & & & 280 \\
\hline $\begin{array}{l}\text { Numero de } \\
\text { propostas } \\
\text { Relatório } \\
\text { Estadual }\end{array}$ & & & \begin{tabular}{|c|}
3.800 propostas dos \\
municípios \\
522 Relatório Estadual \\
Resumido em $5 \mathrm{p}$. \\
para etapa nacional \\
\end{tabular} & 358 propostas & 395 em 3 eixos & \begin{tabular}{|c|}
146 propostas em 7 \\
diretrizes. Para etapa \\
nacional 7 diretrizes \\
nacionais cada um \\
com 5 propostas \\
\end{tabular} & $\begin{array}{c}\text { Para etapa nacional } \\
8 \text { diretrizes cada } \\
\text { uma com } 5 \\
\text { propostas }\end{array}$ \\
\hline
\end{tabular}

${ }^{11} \mathrm{O}$ tema da $14^{\mathrm{a}}$ Conferencia Nacional de saúde foi "Todos usam o SUS! SUS na seguridade social, política pública, patrimônio do povo brasileiro". O logo da $6^{\mathrm{a}}$ Conferencia Estadual de Saúde/SC tinha parte do tema, mas a Conferencia de abertura tinha o tema completo. 
De maneira geral estas Conferências se organizaram com base no temário e eixos indicados pelo Conselho Nacional de Saúde para etapa nacional da plenária. As palestras realizadas e os eixos para os trabalhos de grupos no estado catarinense seguiram essas indicações.

O processo político da organização e as tensões de cada plenária não se refletem nos documentos pesquisados. Avalia-se que alguns elementos deste processo político pode ser recuperado com pesquisa as atas do Conselho Estadual de Saúde que registrou parcamente este processo. Os detalhes dos embates e tensões políticas talvez com entrevistas com os membros da comissão organizadora. Para além do aspecto formal da comissão organizadora, também se desconhece posicionamentos públicos de entidades representantes de trabalhadores e usuários por meio de documentos que apresentaram propostas nas Conferências. Sabe-se que a definição de propostas de uma Conferencia Estadual expressa no seu Relatório Final, que reuniu sempre um pouco mais de mil pessoas dos vários segmentos, não foi um processo linear e nem consensual. Para além de relatar o processo de organização, entende-se que um Relatório Final também deva refletir e descrever como as propostas emergiram e como foram se remodelando ou sendo excluídas no debate estadual. Além de uma sistematização das propostas enviadas pelos 296 municípios para construir o documento base da plenária estadual, por mais esforço que a comissão de relatoria realize de refletir o que foi enviado acaba perdendo a intenção e a originalidade. $O$ esforço e o respeito às propostas que vem dos municípios significa a essência da descentralização e da democracia representativa e participativa.

A proposta que vem das plenárias municipais também revela as necessidades de saúde mais imediatas da população, como também são indicativas do horizonte ideopolitico do SUS. Por exemplo, em 2011 os municípios mandaram para etapa estadual aproximadamente 3.800 propostas, que foram sintetizadas pela comissão de relatoria e subsidiaram os trabalhos de grupos da plenária estadual. Nos grupos estas propostas foram, condensadas, suprimidas ou alteradas/complementadas. Este processo participativo ascendente não é documentado nos Relatórios das Conferências Estaduais. Não tem se observado que a comissão organizadora da etapa estadual tenha deixado para consulta pública o conjunto de propostas que chegaram dos munícipios. Do mesmo modo não fica para consulta pública a síntese que a relatoria faz delas para a plenária estadual.

A organização e realização das Conferências de Saúde é um processo denso de propostas, necessidades de saúde e vocalizações que emergem dos mais variados segmentos, no entanto, este processo participativo que deve levar a proposições para gestão do SUS, ainda merece ser melhor registrado, sistematizado, divulgado e arquivado. Num pais com tão curta tradição participativa nas políticas públicas necessitamos destes registros e que estejam aberto ao acesso público.

\section{4 - Perfil dos delegados das Conferências Estaduais de Saúde em Santa Catarina}

Este item tem por objetivo apresentar os dados colhidos e tabulados de duas pesquisas realizadas durante $5^{\mathrm{a}}$ e a $6^{\mathrm{a}}$ Conferência Estadual de Saúde de Santa Catarina sobre o perfil sócio-político dos participantes. Os Relatórios das Conferências estaduais consultados não dispõem de qualquer informação sobre o perfil dos delegados. 
Dos 296 municípios de Santa Catarina 276 realizaram Conferência Municipal de Saúde em 2007 e inscreveram delegados para a Conferência Estadual $270^{12}$ conforme evidencia a tabela 1 . Na $5^{\text {a }}$ Conferência se inscreveram como delegados titulares 1321 pessoas eleitas nas Conferências Municipais e indicadas por entidades de âmbito estadual, destas estiveram presentes na plenária 1007. Como observadores representantes de entidades estaduais se inscreveram 14 pessoas ( 9 profissionais de saúde, 1 prestador de serviço para o SUS e 04 usuários). Na 6 plenária foram inscritos 1679 delegados, mas se credenciaram 964.

Tabela 1 - Número de delegados inscritos, credenciados e municípios representados por segmento, na $5^{\text {a }}$ e $6^{\text {a }}$ Conferência Estadual de Saúde em 2007 e 2011 respectivamente.

\begin{tabular}{lcccccc}
\hline \multirow{2}{*}{ Segmento } & \multicolumn{2}{c}{$\mathbf{2 0 0 7}$} & \multicolumn{2}{c}{$\mathbf{2 0 1 1}$} & \multicolumn{2}{c}{ Municípios dos inscritos } \\
\cline { 2 - 6 } & Inscritos & Credenciados & Inscritos & Credenciados & $\mathbf{2 0 0 7}$ & $\mathbf{2 0 1 1}$ \\
\hline Gestor & 287 & 223 & 303 & 182 & 214 & 218 \\
Prestador & 102 & 112 & 138 & 59 & 77 & 108 \\
Trabalhador & 271 & 225 & 387 & 259 & 66 & 231 \\
Usuário & 661 & 447 & 851 & 464 & 262 & 278 \\
\hline \multicolumn{1}{c}{ Total } & $\mathbf{1 3 2 1}$ & $\mathbf{1 0 0 7}$ & $\mathbf{1 6 7 9}$ & $\mathbf{9 6 4}$ & - & - \\
\hline
\end{tabular}

Fonte: KRÜGER, T. R., 2007a; KRÜGER, T. R., 2011. Informações das Conferências SES/SC. http://portalses.saude.sc.gov.br/index.php?option=com_content\&view=article $\&$ id=1384\&Itemid=425

Dos dados desta tabela observa-se que os trabalhadores da saúde compõem o segmento menos representativo em termos de municípios na etapa de 2007 e os prestadores privados na etapa de 2011. Nas duas plenárias os usuários compõem o segmento mais representativo. Entre os inscritos da $5^{\text {a }}$ Conferência verifica-se que a composição é respeitada apenas entre os usuários 50,0\%. Dos demais $(20,5$ trabalhadores, 21,8 gestores e 7,7 prestadores) verifica-se que a paridade da composição legal dos delegados presentes não se verifica nos termos da Resolução ${ }^{\circ}$ 333/2003, do Conselho Nacional de Saúde. Os trabalhadores estão com percentuais de inscritos abaixo dos $25 \%$ previstos. Quando se compara o número de credenciados em relação aos inscritos verifica-se que faltaram muitas pessoas, sendo mais representativa a falta de usuários, quase um terço. Neste caso, a representação dos gestores foi superior a recomendada. $\mathrm{O}$ segmento dos prestadores foi o único que o número de participantes foi maior em relação aos inscritos. No entanto, sua paridade ainda está um pouco abaixo conforme a Resolução 333/2003.

Entre os credenciados na $6^{\mathrm{a}}$ Conferência verifica-se que a composição se aproxima do que recomenda a Resolução no 453/2012 do Conselho Nacional de Saúde: 48,1\% usuários, 26,8 trabalhadores, 18,8 gestores e 5,12 prestadores.

Para conhecer o perfil sócio-político dos participantes da $5^{\mathrm{a}}$ e $6^{\mathrm{a}}$ Conferência Estadual de Saúde de Santa Catarina foram entrevistados 201 delegados participantes de 118 municípios catarinenses em 2007 e 437 delegados participantes em 2011. A pesquisa ora apresentada se realizou da seguinte forma. Considerou-se elegível para

\footnotetext{
${ }^{12}$ De acordo com documento "Relação dos Delegados Inscritos" disponibilizado no site da SES/SC: http://portalses.saude.sc.gov.br/index.php?option=com_content\&view=article\&id=1384:60-conferenciaestadual-de-saude\&catid=702:60-conferencia-estadual-de-saude\&Itemid=425. Acesso em 07/02/2015
} 
participar da entrevista delegados credenciados e presentes $5^{\mathrm{a}}$ e $6^{\mathrm{a}}$ Conferência Estadual de Saúde de Santa Catarina. Os pesquisadores ao abordarem os delegados de maneira aleatória explicavam os objetivos e solicitavam a disponibilidade em participar do estudo $^{13}$. O questionário foi elaborado com base no modelo usado pela Secretaria de Gestão Participativa do Ministério da Saúde que em 2003 levantou o perfil dos participantes a $12^{\circ}$ Conferência Nacional de Saúde com intenção de permitir comparações futuras ${ }^{14}$. Na sequencia apresenta-se a tabela 2 com a distribuição dos delegados entrevistados, por segmento e sexo, presentes nas duas plenárias que foram pesquisadas.

Tabela 2 - Distribuição dos delegados entrevistados, por segmento e sexo, presentes na $5^{\mathrm{a}}$ e $6^{\mathrm{a}}$ Conferência Estadual de Saúde em 2007 e 2011 respectivamente.

\begin{tabular}{|c|c|c|c|c|c|c|c|c|c|c|c|c|}
\hline \multirow{2}{*}{ Segmento } & \multicolumn{6}{|c|}{2007} & \multicolumn{6}{|c|}{2011} \\
\hline & Fem & $\%$ & Masc & $\%$ & Total & $\%$ & Fem & $\%$ & Masc & $\%$ & Total & $\%$ \\
\hline Usuários & 53 & 49,1 & 55 & 50,9 & 108 & 53,7 & 111 & 49,0 & 117 & 54,9 & 228 & 52,1 \\
\hline Trabalhadores & 35 & 32,7 & 16 & 17,2 & 51 & 25,4 & 77 & 34,3 & 41 & 19,2 & 118 & 27,0 \\
\hline Gestor & 18 & 16,8 & 17 & 18,0 & 35 & 17,4 & 34 & 15,0 & 40 & 18,7 & 74 & 16,9 \\
\hline Prestador & 1 & 0,9 & 6 & 5,3 & 7 & 3,5 & 2 & 0,9 & 15 & 7,0 & 17 & 0,3 \\
\hline Total & 107 & 53,2 & 94 & 46,8 & 201 & 100 & 224 & 51,2 & 213 & 48,7 & 437 & 100 \\
\hline
\end{tabular}

Fonte: KRÜGER, T. R., 2007a; KRÜGER, T. R., 2011. Informações das Conferências SES/SC. http://portalses.saude.sc.gov.br/index.php?option=com_content\&view=article\&id=1384\&Itemid=425

Em relação a distribuição por sexo dos delegados usuários entrevistados, conforme tabela 3 , a representação nas duas plenárias oscila em poucos percentuais em torno dos 50\%, parece relativamente equilibrado. Quando comparados por segmento observa-se maior predominância do sexo feminino no segmento dos trabalhadores e menor no segmento dos prestadores.

Tabela 3 - Distribuição dos delegados entrevistados da $5^{\mathrm{a}}$ e $6^{\mathrm{a}}$ Conferência Estadual de Santa Catarina por idade e sexo:

\begin{tabular}{ccccccc}
\hline \multirow{2}{*}{ Idade } & \multicolumn{2}{c}{$\mathbf{2 0 0 7}$} & \multicolumn{2}{c}{$\mathbf{2 0 1 1}$} & Média & Média \\
\cline { 2 - 5 } & Feminino & Masculino & Feminino & Masculino & $\mathbf{2 0 0 7}$ & $\mathbf{2 0 1 1}$ \\
\hline 20 a 30 anos & 30 & 14 & 52 & 28 & 21,9 & 18,1 \\
31 a 40 anos & 28 & 21 & 54 & 44 & 24,4 & 22,4 \\
41 a 50 anos & 26 & 28 & 57 & 62 & 26,8 & 27,4 \\
51 a 60 anos & 18 & 21 & 37 & 43 & 19,4 & 18,6 \\
61 a 70 anos & 4 & 9 & 21 & 32 & 6,5 & 12,0 \\
71 ou mais & 1 & 1 & 3 & 4 & 0,99 & 1,6 \\
\hline \multicolumn{1}{c}{ Total } & 107 & 94 & 224 & 213 & 100 & 100 \\
\hline
\end{tabular}

Fonte: KRÜGER, T. R., 2007a; KRÜGER, T. R., 2011. Informações das Conferências SES/SC. http://portalses.saude.sc.gov.br/index.php?option $=$ com_content\&view $=$ article\&id=1384\&Itemid=425

${ }^{13}$ Em cada uma das pesquisas foi apresentado ao candidato à entrevista os dados da aprovação do projeto pelo CEP/CSES/SC e o Termo de Consentimento Livre e Esclarecido. A maioria dos entrevistados dispensou de assinar o Termo. Somente após a autorização do delegado que se fazia a entrevista.

${ }^{14}$ Esta comparação já foi realizada no texto: KRÜGER, T. R.; 5 a Conferência Estadual de Santa Catarina: estudo do perfil sócio-político dos delegados. In. Grifos. Chapecó: Argos, 2007b, p. 319-341. 
Quanto à idade, observa-se na tabela acima que 49,8\% dos entrevistados possuem idade entre 31 e 50 anos, estão no auge de sua vida produtiva e intelectual. Há um número significativo $(13,6 \%)$ de idosos. A pesquisa buscou conhecer também os participantes das Conferências o nível e escolaridade conforme por segmento social representado, conforme tabela 4 .

Tabela 4 - Percentual dos níveis de escolaridade por segmento dos delegados da $5^{\mathrm{a}}$ e $6^{\mathrm{a}}$ Conferência Estadual de Santa Catarina:

\begin{tabular}{|c|c|c|c|c|c|c|c|c|c|}
\hline \multirow{2}{*}{ Escolaridade } & \multicolumn{2}{|c|}{ Usuário } & \multicolumn{2}{|c|}{ Trabalhador } & \multicolumn{2}{|c|}{ Gestor } & \multicolumn{2}{|c|}{ Prestador } & \multirow[t]{2}{*}{ Média } \\
\hline & 2007 & 2011 & 2007 & 2011 & 2007 & 2011 & 2007 & 2011 & \\
\hline Fundamental Incompleto & 17,5 & 1,3 & - & - & - & - & - & - & 9,4 \\
\hline Fundamental Completo & 9,2 & 23,1 & - & - & - & 1,4 & - & - & 11,2 \\
\hline Médio Incompleto & 4,6 & 6,1 & 1,9 & - & - & 2,7 & - & - & 3,8 \\
\hline Médio Completo & 28,7 & 32,3 & 15,6 & 10,2 & 8,5 & 23 & - & 5,9 & 21,7 \\
\hline Superior Incompleto & 8,3 & 12,2 & 5,8 & 7,6 & 17,1 & 4,1 & 14,2 & 11,8 & 10,1 \\
\hline Superior Completo & 16,6 & 13,5 & 23,5 & 20,3 & 31,4 & 35,1 & 42,8 & 41,2 & 28 \\
\hline Especialização & 13,8 & 9,6 & 49 & 54,2 & 34,2 & 28,4 & 42,8 & 41,2 & 35,9 \\
\hline Mestrado & 0,92 & 0,9 & 1,9 & 6,8 & 5,7 & 5,4 & - & - & 3,6 \\
\hline Doutorado & - & 0,9 & 1,9 & 0,8 & - & - & - & - & 1,2 \\
\hline Total & 100 & 100 & 100 & 100 & 100 & 100 & 100 & 100 & 100 \\
\hline
\end{tabular}

Fonte: KRÜGER, T. R., 2007a; KRÜGER, T. R., 2011. Informações das Conferências SES/SC. http://portalses.saude.sc.gov.br/index.php?option=com_content\&view=article \&id=1384\&Itemid=425

Predominou nas duas plenárias a presença de membros com nível universitário de escolaridade, sendo quase $40 \%$ os que possuem além da graduação algum nível e pós- graduação. Os maiores níveis de escolaridade estão entre os prestadores, gestores e trabalhadores.

No segmento usuário a escolaridade dos delegados da etapa de 2011 foi maior do que de 2007, no entanto a grande maioria, 60,0\%, possui escolaridade até o segundo grau e 31,4\% graduação e pós-graduação. Como visto na tabela anterior, as Conferências se compõem de delegados em plena maturidade da vida intelectual e profissional e quando se cruza com os indicadores dos níveis educacionais, avalia-se que seus participantes fazem parte de uma elite social e intelectual tanto para os padrões nacionais como para o estadual. Isto se comprova quando vimos que o Brasil, mesmo contando com níveis crescentes de escolaridade, o percentual de brasileiros com nível superior completo passou de 4,4\%, em 2000, para 7,9\% em 2010, na região Sul este percentual saiu de $4,8 \%$ para $8,9 \%$ (BRASIL, 2012). Particularmente Santa Catarina possui dados semelhantes à média nacional e regional, em 2008 9,49\% da população possuía 15 anos ou mais anos de escolaridade e em 2011 este índice subiu para 10,2\%. Em 2011 a população adulta que tinha menos de 1 ano de escolaridade era 7,5\%, no mesmo período 7,67\% possuía de 1 a 3 anos e $25,7 \%$ de 4 a 7 anos de escolaridade (SANTA CATARINA, 2013). 
Tabela 5 - Percentual da distribuição dos delegados da $5^{\text {a }}$ e $6^{\text {a }}$ Conferência Estadual de Santa Catarina por escolaridade e sexo:

\begin{tabular}{|c|c|c|c|c|c|c|c|}
\hline \multirow[b]{2}{*}{ Escolaridade } & \multicolumn{2}{|c|}{2007} & \multicolumn{2}{|c|}{2011} & \multirow{2}{*}{$\begin{array}{c}\text { Média } \\
\text { Escolaridade }\end{array}$} & \multirow{2}{*}{$\begin{array}{c}\text { Média } \\
\text { Feminino }\end{array}$} & \multirow{2}{*}{$\begin{array}{c}\text { Média } \\
\text { Masculino }\end{array}$} \\
\hline & $\begin{array}{c}\text { Feminino } \\
\%\end{array}$ & $\begin{array}{c}\text { Masculino } \\
\%\end{array}$ & $\begin{array}{c}\text { Feminino } \\
\%\end{array}$ & $\begin{array}{c}\text { Masculino } \\
\%\end{array}$ & & & \\
\hline $\begin{array}{l}\text { Fundamental } \\
\text { Incompleto }\end{array}$ & 5,6 & 13,8 & 0 & 1,4 & 5,2 & 2,8 & 7,6 \\
\hline $\begin{array}{l}\text { Fundamental } \\
\text { Completo }\end{array}$ & 3,7 & 6,3 & 10,1 & 14,4 & 8,6 & 6,9 & 10,3 \\
\hline $\begin{array}{l}\text { Médio } \\
\text { Incompleto }\end{array}$ & 2,8 & 3,1 & 2,6 & 4,2 & 3,2 & 2,7 & 3,6 \\
\hline $\begin{array}{l}\text { Médio } \\
\text { Completo }\end{array}$ & 18,7 & 23,4 & 21,6 & 27 & 22,6 & 20,1 & 25,2 \\
\hline $\begin{array}{l}\text { Superior } \\
\text { Incompleto }\end{array}$ & 9,3 & 9,5 & 10,1 & 8,4 & 9,3 & 9,7 & 8,9 \\
\hline $\begin{array}{l}\text { Superior } \\
\text { Completo }\end{array}$ & 21,5 & 23,4 & 18,9 & 20,9 & 21,2 & 20,2 & 22,1 \\
\hline Especialização & 37,3 & 16 & 31,7 & 21,4 & 26,6 & 34,5 & 18,7 \\
\hline Mestrado & 0,9 & 3,1 & 3,5 & 2,3 & 2,5 & 2,2 & 2,7 \\
\hline Doutorado & 0 & 1 & 1,3 & 0 & 0,5 & 0,6 & 0,5 \\
\hline & 100 & 100 & 100 & 100 & 100 & 100 & 100 \\
\hline
\end{tabular}

Fonte: KRÜGER, T. R., 2007a; KRÜGER, T. R., 2011. Informações das Conferências SES/SC. http://portalses.saude.sc.gov.br/index.php?option=com_content\&view=article\&id=1384\&Itemid=425

Os homens delegados das duas Conferências com maior nível de escolaridade em cada um dos níveis apresentados na tabela 5, do fundamental a graduação, revelam maior escolaridade. Este percentual se inverte quando se trata da pós-graduação, no qual as mulheres apresentam maior nível de escolaridade, o que representou em $200726 \%$ dos participantes e em 2011 35\%. Vale destacar que de uma etapa para outra também diminuiu o numero de participantes com ensino fundamental incompleto, especialmente na população masculina este percentual foi quase de $10 \%$.

Tabela 6 - Frequência da distribuição dos delegados da $5^{a}$ e $6{ }^{\text {a }}$ Conferência Estadual de Santa Catarina dos segmentos por formação na área da saúde.

\begin{tabular}{lcccccc}
\hline \multirow{2}{*}{ Formação na área da saúde } & \multicolumn{2}{c}{$\mathbf{2 0 0 7}$} & \multicolumn{2}{c}{$\mathbf{2 0 1 1}$} & \multicolumn{2}{c}{ Total } \\
\cline { 2 - 7 } & Sim & Não & Sim & Não & $\begin{array}{c}\text { Não } \\
\text { respondeu }\end{array}$ \\
\hline Gestor & 24 & 11 & 33 & 39 & 1 & 107 \\
Prestador & 4 & 3 & 12 & 5 & 1 & 24 \\
Trabalhadores & 42 & 9 & 103 & 13 & 4 & 167 \\
Usuários & 18 & 90 & 164 & 57 & 5 & 329 \\
\hline \multicolumn{1}{c}{ Total } & 88 & 113 & 312 & 114 & 11 & 638
\end{tabular}

Fonte: KRÜGER, T. R., 2007a; KRÜGER, T. R., 2011. Informações das Conferências SES/SC. http://portalses.saude.sc.gov.br/index.php?option=com_content\&view=article\&id=1384\&Itemid=425

Possuem formação na área da saúde $43,7 \%$ dos delegados entrevistados da Conferência de 2007 e 71,3\% dos entrevistados em 2011. E significativo à alteração do perfil dos usuários de uma plenária para outra de como a maioria possui alguma formação na área da saúde. Como pudemos observar a seguir na tabela 7 a formação dos delegados é bastante diversa em diferentes áreas da saúde das ciências humanas e 
sociais. Há um significativo número de técnicos, mas também um importante número de entrevistados em que a pesquisa não conseguiu identificar a área de formação.

Tabela 7 - Frequência da distribuição dos delegados da $5^{\mathrm{a}}$ e $6^{\mathrm{a}}$ Conferência Estadual de Santa Catarina por curso de formação e segmento, em 2007 e 2011.

\begin{tabular}{|c|c|c|c|c|c|c|c|c|c|}
\hline \multirow{2}{*}{ Curso de formação } & \multicolumn{2}{|c|}{ Gestor } & \multicolumn{2}{|c|}{ Prestador } & \multicolumn{2}{|c|}{ Trabalhadores } & \multicolumn{2}{|c|}{ Usuários } & \multirow{2}{*}{ Total } \\
\hline & 2007 & 2011 & 2007 & 2011 & 2007 & 2011 & 2007 & 2011 & \\
\hline Administração & 5 & 10 & 2 & 6 & 1 & 3 & 1 & 11 & 39 \\
\hline $\begin{array}{l}\text { Ciências Físicas e } \\
\text { Biológicas }\end{array}$ & - & 2 & - & - & 1 & 1 & 1 & 4 & 9 \\
\hline Contador e Técnico Cont & - & 2 & - & - & - & 2 & 2 & 9 & 15 \\
\hline Direito & - & 2 & 1 & - & 1 & 1 & 3 & 6 & 14 \\
\hline Ecologia/Naturologia & - & & - & & - & & 2 & 1 & 3 \\
\hline Economia & - & & 1 & 1 & 1 & 1 & 1 & - & 5 \\
\hline Enfermagem & 10 & 12 & 1 & 4 & 14 & 48 & 1 & 5 & 97 \\
\hline Educador Físico & - & 1 & - & - & - & 1 & - & - & 2 \\
\hline $\begin{array}{l}\text { Engenharia de } \\
\text { Manutenção/ Sanitária }\end{array}$ & - & - & - & - & - & 1 & - & 1 & 2 \\
\hline Farmácia & 1 & - & 1 & - & 1 & 6 & - & 2 & 11 \\
\hline $\begin{array}{l}\text { Filosofia/Ciências } \\
\text { Sociais/História }\end{array}$ & - & 1 & - & - & - & & 10 & 2 & 13 \\
\hline Fisioterapia & 1 & 2 & - & - & - & 5 & 1 & 3 & 12 \\
\hline $\begin{array}{l}\text { Gestão Pública/RH } \\
\text { Gestão Hospitalar }\end{array}$ & 1 & 2 & - & - & - & 1 & 1 & 2 & 7 \\
\hline Sistema Informação/ Comp & 1 & 3 & - & - & - & - & - & - & 4 \\
\hline Letras & 1 & 1 & 1 & - & 1 & - & 2 & & 6 \\
\hline Magistério & - & - & - & - & - & 1 & 2 & 4 & 7 \\
\hline Matemática & 1 & - & - & - & - & - & - & - & 1 \\
\hline Medicina & 1 & - & - & - & 2 & 4 & - & - & 7 \\
\hline Nutrição & - & 1 & - & - & 1 & 1 & 1 & - & 4 \\
\hline Odontologia & 1 & 3 & - & 2 & 2 & 11 & 1 & 1 & 21 \\
\hline Pedagogia & 1 & 5 & - & - & 1 & 3 & 4 & 15 & 29 \\
\hline Psicologia & - & 1 & - & - & 1 & 7 & 3 & 2 & 14 \\
\hline Publicidade/Marketing & - & - & - & - & - & - & 2 & 1 & 3 \\
\hline Química & 1 & - & - & - & - & - & - & - & 1 \\
\hline Serviço Social & 2 & 5 & - & - & 1 & 8 & 4 & 7 & 27 \\
\hline Técnico de enfermagem & 1 & 1 & - & 1 & - & 2 & - & 5 & 13 \\
\hline Teologia & - & - & - & - & - & - & 1 & - & 1 \\
\hline Outro nível superior & - & 2 & - & 1 & 1 & 1 & - & 2 & 7 \\
\hline Técnico diversas áreas & 1 & 1 & - & - & - & 2 & - & 111 & 115 \\
\hline Não identificado & 8 & 17 & - & 2 & 24 & 8 & 65 & 34 & 158 \\
\hline Total & 35 & 74 & 7 & 17 & 51 & 118 & 43 & 194 & \\
\hline
\end{tabular}

Fonte: KRÜGER, T. R., 2007a. KRÜGER, T. R., 2011. Informações das Conferências SES/SC.

http://portalses.saude.sc.gov.br/index.php?option=com_content\&view=article\&id=1384\&Itemid=425

Os dados da pesquisa evidenciam, na tabela 8 , que $58,6 \%$ na $5^{\text {a }}$ Conferência e $54,7 \%$ na $6^{\text {a }}$ Conferência dos entrevistados se caracterizaram como empregados. No entanto, no segmento usuário se observa a maior variedade de ocupações e é ainda neste segmento que se encontram a maioria de aposentados, de autônomos e de desempregados. 
Tabela 8 - Frequência da distribuição dos delegados da $5^{\mathrm{a}}$ e $6^{\mathrm{a}}$ Conferência Estadual de Saúde de Santa Catarina dos segmentos por ocupação em 2007 e 2011.

\begin{tabular}{l|c|c|c|c|c|c|c|c|c|c}
\hline \multicolumn{1}{c|}{ Ocupação } & \multicolumn{2}{c|}{ Gestor } & \multicolumn{2}{c|}{ Prestador } & \multicolumn{2}{c|}{ Trabalhador } & \multicolumn{2}{c}{ Usuário } & \multicolumn{2}{c}{ Total } \\
\hline & $\mathbf{2 0 0 7}$ & $\mathbf{2 0 1 1}$ & $\mathbf{2 0 0 7}$ & $\mathbf{2 0 1 1}$ & $\mathbf{2 0 0 7}$ & $\mathbf{2 0 1 1}$ & $\mathbf{2 0 0 7}$ & $\mathbf{2 0 1 1}$ & $\mathbf{2 0 0 7}$ & $\mathbf{2 0 1 1}$ \\
\hline Aposentado & - & - & 1 & - & 2 & 3 & 20 & 59 & 23 & 62 \\
\hline Autônomo & - & - & 1 & 2 & 1 & 3 & 24 & 42 & 26 & 53 \\
\hline Desempregado & - & - & - & - & - & - & 6 & 3 & 6 & 3 \\
\hline Empregado & 35 & 68 & 4 & 15 & 47 & 03 & 52 & 100 & 138 & 283 \\
\hline Empregador & - & - & 1 & - & - & 1 & 4 & 4 & 5 & 5 \\
\hline Estudante & - & - & - & - & 1 & - & 1 & - & 2 & - \\
\hline Agricultor & - & - & - & - & - & - & - & 14 & 14 \\
\hline Outras ocupações & - & 6 & - & - & - & - & - & 5 & - & 11 \\
\hline Não respondeu & - & - & - & - & - & 2 & 1 & 1 & 1 & 2 \\
\hline
\end{tabular}

Fonte: KRÜGER, T. R., 2007a. KRÜGER, T. R., 2011. Informações das Conferências SES/SC. http://portalses.saude.sc.gov.br/index.php?option $=$ com content $\&$ view $=$ article $\&$ id $=1384 \&$ Itemid $=425$

A maioria $(65,2 \%)$ dos delegados entrevistados nas duas plenárias revelou não possuir plano privado de saúde conforme evidencia a tabela 9.

Tabela 9 - Percentual dos delegados da $5^{\mathrm{a}}$ e $6^{\mathrm{a}}$ Conferência Estadual de Saúde de Santa Catarina dos segmentos que possuem plano privado de saúde, em 2007 e 2011.

\begin{tabular}{lccccccc}
\hline \multirow{2}{*}{ Possui plano de saúde } & \multicolumn{2}{c}{$\mathbf{2 0 0 7}$} & \multicolumn{2}{c}{$\mathbf{2 0 1 1}$} & \multirow{2}{*}{ Média SUS } & $\begin{array}{c}\text { Média } \\
\text { Privado }\end{array}$ \\
\cline { 2 - 6 } & SUS \% & $\begin{array}{c}\text { Serv. } \\
\text { Privado \% }\end{array}$ & SUS \% & $\begin{array}{c}\text { Serv. } \\
\text { Privado \% }\end{array}$ & & \\
\hline Gestor & 61,1 & 38,8 & 70,3 & 29,7 & 65,7 & 34,25 \\
Prestador & 28,5 & 71,4 & 52,9 & 47,1 & 40,7 & 59,25 \\
Trabalhadores & 62,0 & 38,4 & 63,8 & 36,2 & 62,9 & 37,3 \\
Usuários & 72,2 & 26,8 & 63,8 & 36,2 & 68,0 & 31,5 \\
\hline & Média Total & 66,1 & 33,9 & 64,3 & 35,8 & 65,2 & 34,85 \\
\hline
\end{tabular}

Fonte: KRÜGER, T. R., 2007a. KRÜGER, T. R., 2011. Informações das Conferências SES/SC. http://portalses.saude.sc.gov.br/index.php?option=com_content\&view=article\&id=1384\&Itemid=425

O percentual $(34,8 \%)$ de detentores de plano de saúde que participaram das duas Conferências está acima nacional que é de $24,7 \%$ da população. Em 2002, a proporção de brasileiros com planos privados de saúde era 17,9\%. Porém, a cobertura pela saúde privada é concentrada como reflete este exemplo, o estado de São Paulo tem a maior cobertura, com 43,6\% da população com plano de saúde, enquanto no Acre apenas $5,6 \%$ das pessoas possuem o serviço contratado. (BRASIL, 2013).

É interessante notar que a posse de plano de saúde pela grande maioria dos delegados da Conferência revela uma das maiores contradições na defesa do sistema público de saúde. As proposições em defesa do serviço público terminam se contrapondo à realidade do cotidiano e às necessidades individuais para que haja resolução dos problemas de modo mais imediato (KRÜGER, 2005, p. 254). 
A procura pelos serviços do SUS também acontece pelos detentores de planos de saúde, no caso os entrevistados em 2007, apenas os trabalhadores detentores de planos privados revelaram não ter procurado o SUS na última consulta. Dos gestores $61,1 \%$ procuraram o SUS na última consulta, $72,2 \%$ dos usuários e $28,5 \%$ dos prestadores

Sobre a participação política dos entrevistados, os usuários $173(75,8 \%) \mathrm{em}$ 2011 afirmaram que participam de algum conselho de direito ou política social, de algum sindicato, federação, associação ou pastoral. Os trabalhadores $45,7 \%$ e os gestores $65,4 \%$ estão envolvidos em algum espaço de participação política. Já a pesquisa com os delegados da plenária de 2007 indicou sobre a participação política, que os gestores têm um percentual semelhante $(65,8 \%)$, os usuários $(40,7)$ e os trabalhadores $(27,45)$ abaixo quando comparamos com os entrevistados em 2011.

\section{Conclusões}

Esta memória quase que linear das Conferências Estaduais de Saúde e a apresentação do perfil dos participantes nas plenárias de 2007 e 2011 teve a intenção de recuperar um pouco desta história e conhecer os sujeitos que participam das Conferências com a responsabilidade de avaliar a política de saúde e fazer proposições para os anos seguintes.

Esta pesquisa sobre a memória das Conferências Estaduais de Saúde de Santa Catarina nos indica que sua organização, realização e relatoria foram conduzidas por técnicos, gestores e entidades representativas de usuários e trabalhadores muito vinculados a administração central da SES, ao CES e técnicos provenientes da capital do estado. Ou seja, parece pouca representatividade de sujeitos sociais de âmbito estadual ou do interior do estado na organização destas plenárias. Ficou evidente nos dados aqui apresentados o credenciamento de pessoas vindas da maioria dos municípios catarinenses, mas parece que isto não tem significado participação no planejamento e organização deste grande evento da saúde pública catarinense.

A falta de sistematização e arquivo dos documentos destas plenárias deixam interrogações sobre o significado e importância de suas proposições junto ao Conselho Estadual de Saúde e a Secretaria de Estado da Saúde. Em que medida o Conselho Estadual tem zelado por estas proposições que refletem as necessidades de saúde da população catarinense? E a Secretaria de Estado se pauta nas proposições das plenárias para elaborar o Plano Plurianual e a Programação Anual de Saúde? Alguns documentos das ultimas Conferências colocados de forma relativamente dispersa no site da Secretaria de Estado e sem uma melhor elaboração será que significa socialização das informações? O acumulo de propostas das Conferências Municipais poderia também ser divulgado como a base trabalha para plenária Estadual?

Sobre o perfil sócio-político dos participantes os dados das pesquisas nos indicam que existe uma heterogeneidade na formação e na ocupação. Isto retrata a legitimidade social do tema saúde, mas também pode ser um reflexo do conceito ampliado de saúde disseminado pela Reforma Sanitária. No entanto, o credenciamento dos delegados nem sempre revelou uma paridade na composição conforme prevê a Resolução $n^{\circ} 333 / 2003$, do Conselho Nacional de Saúde e agora a sua substitutiva, a Resolução $\mathrm{n}^{\circ}$ 453/2012, que deve ser de 50\% representantes de usuários, $25 \%$ trabalhadores e $25 \%$ divididos entre gestores públicos e prestadores privados 
contratualizados. A participação dos delegados por sexo parece relativamente equilibrada, em torno dos $50 \%$ e em termos de idade predomina o adulto jovem no auge de sua vida produtiva e intelectual. Quanto a escolaridade, avalia-se que seus participantes fazem parte de uma elite social e intelectual tanto para os padrões nacionais como para o estadual, pois aproximadamente $65 \%$ dos participantes possuem graduação e pós-graduação. Deste perfil também se destaca o número significativo dos que possuem plano privado de saúde, mas contraditoriamente são representantes de vários segmentos sociais no maior evento avaliativo e propositivo da relação da saúde pública. Talvez não seja demais inferir que a escolha dos delegados para a conferência estadual possua um corte de escolaridade, situação funcional e melhor condição socioeconômica.

Quanto ao perfil avalia-se que faltou melhor precisão do vinculo empregatício dos entrevistados em 2011, pois nos parece que a maioria, independente do segmento social, tem vinculo de trabalho no setor público. A pesquisa realizada com os participantes da plenária em 2007 indicou a majoritária participação de funcionários públicos com vínculo municipal (49\%). Isto provavelmente está relacionado à centralidade do setor público na área de saúde, especialmente na atenção básica nos municípios, tanto como prestador de serviços públicos, financiador e regulador da provisão privada de serviços.

Sugere-se que as organizações das plenárias realizem levantamento do perfil dos participantes em parcerias com as universidades, assim como nestas parcerias pode-se prever melhor registro e sistematização de todo o processo organizativo e Relatório Final das plenárias.

Por fim espera-se que este estudo seja um passo para futuras pesquisas sobre o processo participativo na saúde pública em Santa Catarina. Neste estado ainda precisa ser melhor estudado e pesquisado a particularidade da história da Reforma Sanitária; a implementação do SUS; as ações do Fórum Popular de Saúde, a formação e trajetória do Conselho Estadual de Saúde; a organização, realização e implementação das proposições Conferências Estaduais de Saúde e o perfil dos diferentes sujeitos sociais que integram. Estas propostas não invalidam estudos de âmbito municipal ou regional. Pois na produção do conhecimento científico é importante que tratarmos do particular para o geral como do geral para o particular. Estas pesquisas podem realizar analises sobre a representatividade dos segmentos e aspectos relacionados aos seus compromissos com o direito a saúde e o SUS.

\section{Referencias}

BRASIL. Resolução CNS $n^{\circ}$ 453, de 10 de maio de 2012. Diretrizes para instituição, reformulação, reestruturação e funcionamento dos Conselhos de Saúde.

BRASIL. Percentual da população que tem plano de saúde aumenta para 24,7\%. Agencia Brasil de Comunicação - EBC. In. http://memoria.ebc.com.br/agenciabrasil/noticia/2013-1129/percentual-da-populacao-que-tem-plano-de-saude-aumenta-para-247. Acesso em 08/02/2015 BRASIL. Censo Número de brasileiros com graduação cresce 109,83\% em 10 anos. In. http://portal.mec.gov.br/index.php?option=com_content\&view=article\&id=17725 acesso em 07/02/2015.

BRAVO, M. I. Gestão democrática na saúde: o potencial dos conselhos. In. Política social e democracia. São Paulo: Cortez, 2001. 
KRÜGER. T. R. Os fundamentos ideo-políticos das Conferências Nacionais de Saúde. Recife: PGSS/UFPE, 2005, Tese de Doutorado.

KRÜGER, T. R. Projeto de pesquisa Conferência Estadual de Saúde/SC: o perfil dos seus participantes. Florianópolis. UFSC/CSE/DSS, 2007a.

KRÜGER, T. R.; $5^{\text {a }}$ Conferência Estadual de Santa Catarina: estudo do perfil sócio-político dos delegados.In. Grifos. Chapecó: Argos, 2007b, p. 319-341. Disponível em http://bell.unochapeco.edu.br/revistas/index.php/grifos/article/view/185

KRÜGER, T. R.; et al..A organização e a dinâmica participativa dos segmentos sociais nas Conferências Municipais de Saúde. In. Emancipação, Ponta Grossa, 12(1): 119-130, 2012. Disponível em http://www.revistas2.uepg.br/index.php/emancipacao

KRÜGER, T. R.; et al. As proposições das Conferências de Saúde e os Planos Municipais de Saúde: um estudo em municípios de Santa Catarina. In. Saúde em debate. Rio de Janeiro. v. 35, n. 91, out./dez. 2011, p. 508-521.

KRÜGER, T. R. Projeto de pesquisa Conferência Estadual de Saúde/SC: organização, perfil dos seus participantes e significados das proposições. Florianópolis. UFSC/CSE/DSS, 2011.

MAGAJEWSKI, Flávio. A História das Conferências de Saúde em Santa Catarina. In. http://conselholocalsaudecentro.blogspot.com.br/2012/03/historia-das-conferencias-de-saudeem.html. acesso 11/03/2016

SANTA CATARINA. Números da educação de Santa Catarina. In. Caderno de Indicadores de Santa Catarina e suas regiões 2013. Secretaria de Estado da Fazenda. Florianópolis, 2013, 189p. SANTA CATARINA. Portaria $\mathrm{n}^{\circ} 387$ de $1^{\circ}$ de junho de 2015, publicada na edição $\mathrm{n}^{\circ} 20.079$ do DOE/SC. Convocação da $7^{\text {a }}$ Conferência Estadual de Saúde 